\title{
Lightweight construction design with bearing surfaces. Thin-walled structures
}

\section{Diseño de construcción ligera con superficies portantes. Estructuras de paredes delgadas}

Susana Palacios Rodríguez (Main Author)

Department of Construction and Architectural Technology. Escuela Técnica Superior de Arquitectura de Madrid Universidad Politécnica de Madrid

Avda. Juan de Herrera, 4. 28040 Madrid (Spain)

susana.palaciosr@alumnos.upm.es

Jesús Anaya Díaz (Corresponding Author)

Department of Construction and Architectural Technology. Escuela Técnica Superior de Arquitectura de Madrid Universidad Politécnica de Madrid

Avda. Juan de Herrera, 4. 28040 Madrid (Spain)

jesus.anaya@upm.es

\section{Borja Cruz López}

Building Structures and Physics Department. Escuela Técnica Superior de Arquitectura de Madrid

Universidad Politécnica de Madrid

Avda. Juan de Herrera, 4. 28040 Madrid (Spain)

b.cruz@alumnos.upm.es

Manuscript Code: 1347

Date of Acceptance/Reception: 16.08.2019/03.02.2019

DOI: $10.7764 / R D L C .18 .2 .398$

\section{Abstract}

This article examines the supporting capacities of the foam-cored metal composites and the assembly methods. The type of sandwich panel chosen is the triple tongue-and-groove refrigeration panel, the operation of which is the basis for calculating its structural capacity. The results of the research on these panels show us conclusions that allow advances in a constructive system demanded in contemporary architectures and markets; Lightweight, pre-industrialized, digitizable, easily assembled and energetically sustainable.

Keywords: Sandwich panel structure; light-frame structure; industrialization, easy assembled, digital production

\section{Resumen}

Este artículo estudia las capacidades portantes de los composites metálicos con núcleo de espuma y los métodos de ensamblado. El tipo de panel sandwich elegido es el panel frigorífico de triple machihembrado, siendo el funcionamiento de éste la base de cálculo de su capacidad estructural. Los resultados de la investigación sobre estos paneles nos muestran conclusiones que permiten avances en un sistema constructivo demandado en las arquitecturas y mercados contemporáneos; ligero, preindustrializado, digitalizable, de fácil ensamblado y energéticamente sostenible.

Palabras clave: Estructura de panel sándwich, estructura de acero ligero, industrialización, fácil ensamblaje, producción digital.

\section{Introduction}

The construction of contemporary architecture defined by parametric geometric as shown by (Fraile, 2014), demands a constructive definition with light, high moulding capacity and high strength materials. The configuration as structural shells (e.g. nature geometries (Elipe \& Díaz 2018) is solved by self-supporting constructive elements, built with metal composite panels with foam core, whose assemble capacity provides the conformation of continous structural shapes(Anaya, 2014).

This preliminary hypothesis sets up the path of study. This research analyses point after point the mechanical characteristics and behaviour, depending on formal and constructive solutions, and the election of the material. For this paper, a panel (sandwich type) with triple tongue-and-groove joint is selected.

\section{Description of the problem}

The main objective of this research is the determination of the structural behaviour of constructive configurations of rigid geometries with composite metal panel with polyurethane foam core, the production methodology for the 
definition of panelised surfaces and their connection systems, as "shape based" and single-hull structures (Koschade, 2006).

Out of the several possible themes of study in the development of composite materials in the field of construction, we have opted for focusing on one made out of a core of foam and two metal sheet faces, which we find well suited for the design of "shape based" and single-hull structures.

This material is one of the most economic and easily accessible in the current construction sector. Its mechanical behaviour is excellent as far as putting up shape based and single-hull structures is concerned.

The origins of sandwich panels in residential construction come from industrial developments and social housing in emerging or developing countries. They also allow for a quick response in natural disasters and shelters for refugees. These have proven effective in industrial developments and nowadays, are used as permanent solutions in urban design.

This research done on the structural behaviour of these panels under in-plane forces is innovative and the good results, as far as the possibility of employing them as bearing walls is concerned, is demonstrated by experimental tests.

State of Art

\section{Materials and theorical study. The influence of light gauge steel framing}

First references in the design of light gauge steel framing structures appeared in the United States of America. In February 1939, AISI (The American Iron and Steel Institute) set up a technical committee with the goal of developing a specification for the design of this kind of structures. Research work was conducted at Cornell University, led by Professor George Winter. In 1946, the Specification for the Design of Light Gauge Steel Structural Members was published, being the first standard on cold formed structures. In these first works, the elastic plate buckling solution was based on Lundquist \& Stowell (1943) who extend the work of Timoshenko \& Gere (1936) by providing practical methods for calculating the stability of plates. The effective width solution was based on the experimental corrections (Winter, 1952). Since 1946 following versions of the Specification, have been added and implemented to reflect the latest research in cold formed profiles. From 1946 to 1986, the Allowable Stress Design (ASD), was used as the unique method approved by AISI Specification.

In 1978, a new method, Load and Resistance Factor Design (LRFD), was implemented. AISI published the first edition with this method in 1991, and in 1996 both ASD and LRFD methods were presented in the same publication. Since then, both ways of design can be used at the convenience of the engineer.

Nevertheless, LRFD method supposes a notable advance over ASD, because it takes into consideration various levels of uncertainty and variability in the estimation of strength and loads, as well as the incorporation of probabilistic models that allow obtain a more consistent reliability in the design. LRFD method is implemented by Canadian regulations, that call it LSD (Limit States Design), and by Eurocodes (Limit States).

The method to calculate the resistance under loads in cold formed steel sections is based on the effective width solution that finds local, distortional and general buckling, taking into account each element in isolation, without considering the influence of adjacent elements, that is, performing an elastic buckling analysis for the entire cross-section.

Since the new law of 2001 AISI, the Direct Strength Method (DSM) is introduced and it is adopted as an alternative design method from 2004 on, also included as such in Australia/New Zealand standards. This method evaluates simultaneously the three types of buckling in steel members, that means, a refocus on research. DSM uses the properties of gross cross sections but requires an exact analysis of the behaviour of the buckling members(Yu \& Chen, 2016).

\section{Methodology}

The research is based on an empirical and demonstrative methodology on the theoretical studies and hypothesis posed in the description of the problem.

A theoretical study based on finite strip elements design of the joint between panels has been done. This joint has been modelled as a vertical structural member. For that purpose, it has been analyzed using CUFSM, a Finite Strip Elastic 
Buckling Analysis Application developed by the Thin- Walled Structure group, from Johns Hopkins University, leaded by Professor Ben Schafer.

The application analyses the thin wall section according to the semi-analytic finite strip method, a variant of the common finite elements method. Sections are discretized in strips or longitudinal elements, based on these strips, to formulate elastic and geometric stiffness matrices(Smith, Arwade, Schafer, \& Moen, 2016). The program allows to explore possible transverse instabilities of a light gauge steel member (Li \& Schafer, 2010).

The characteristics of the folding model are presented in Figure 1.

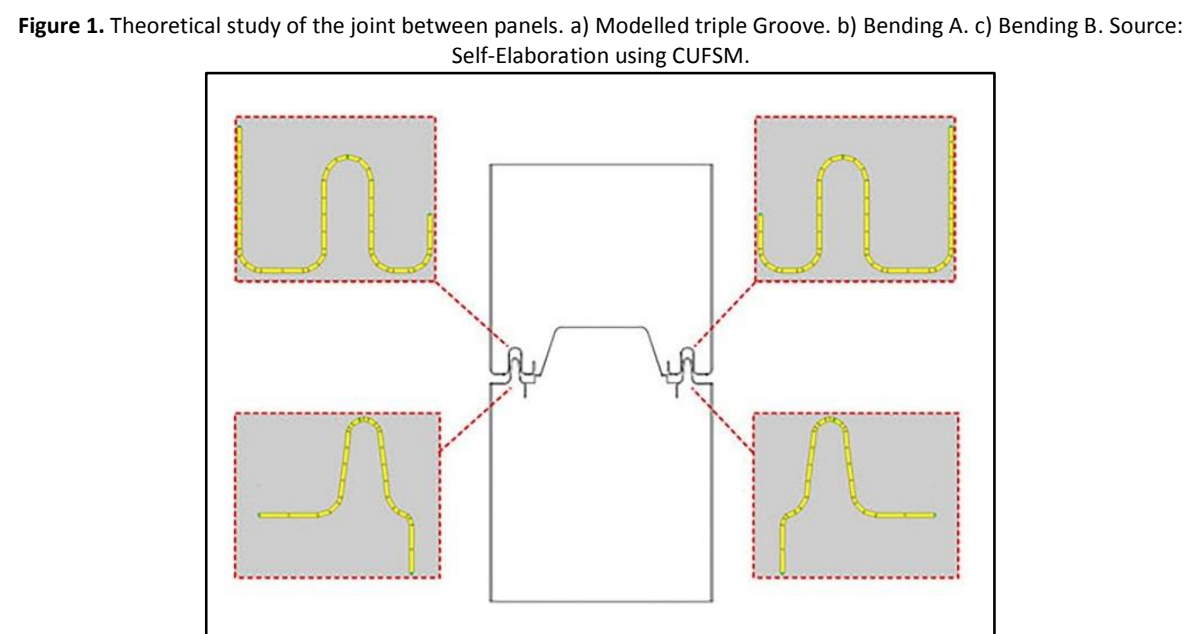

a)

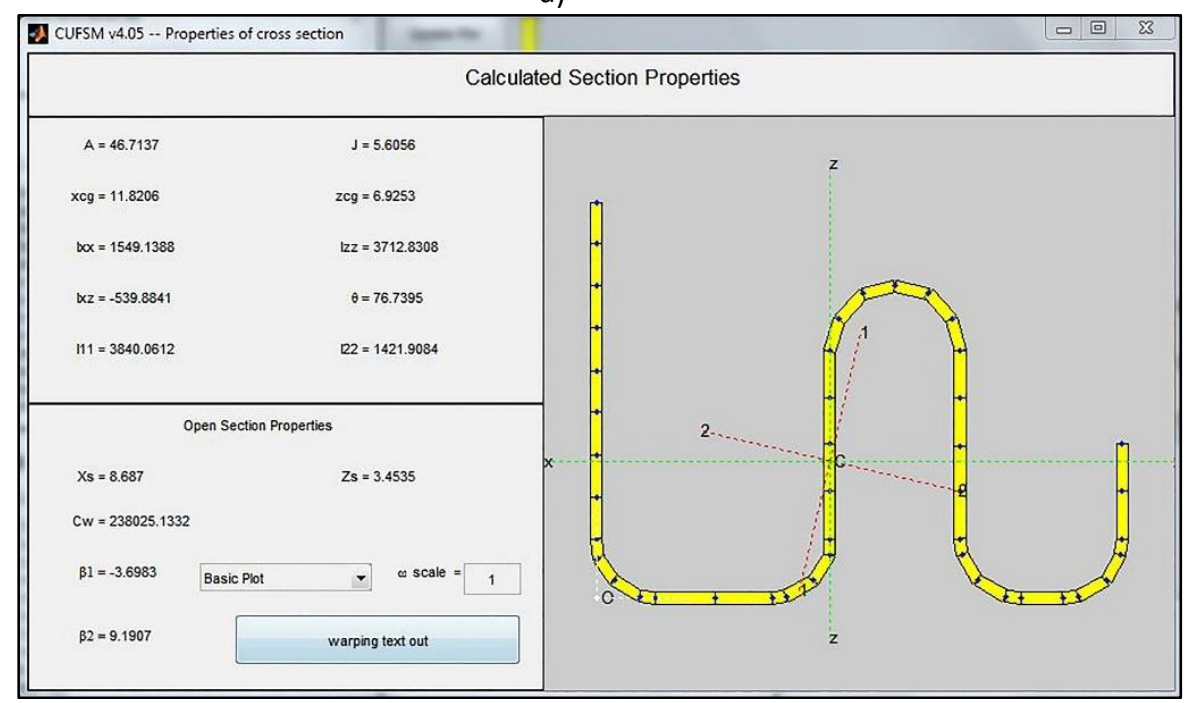

b)

c)

The following Figure 2 shows the stress distribution obtained in the analysis of the plate zone considered to be under compression. 
Figure 2. Analysis of the bending according to the formulation of the DSM; a) Bending A. b) Bending B. Source: Self-Elaboration using CUFSM.

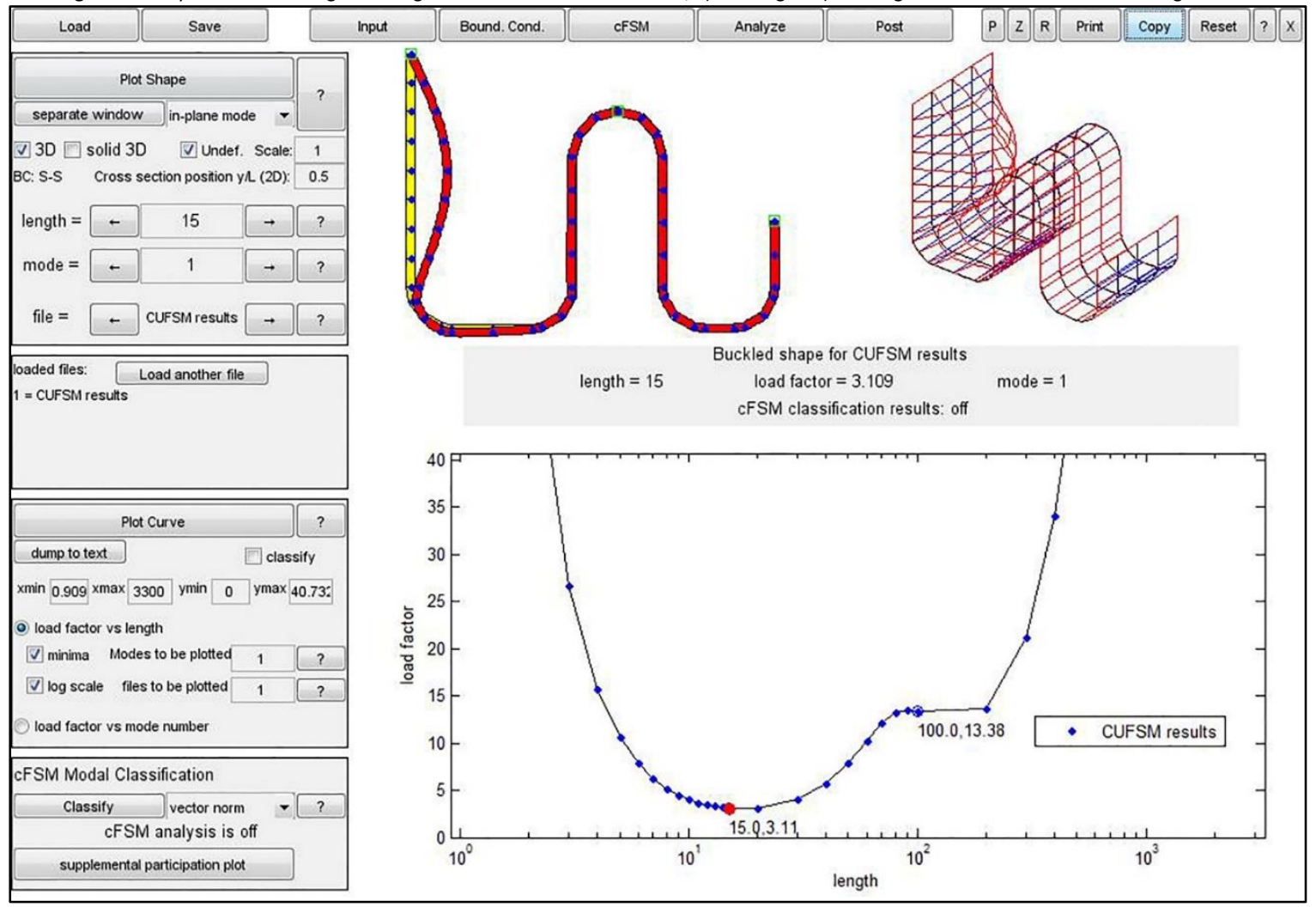

a)

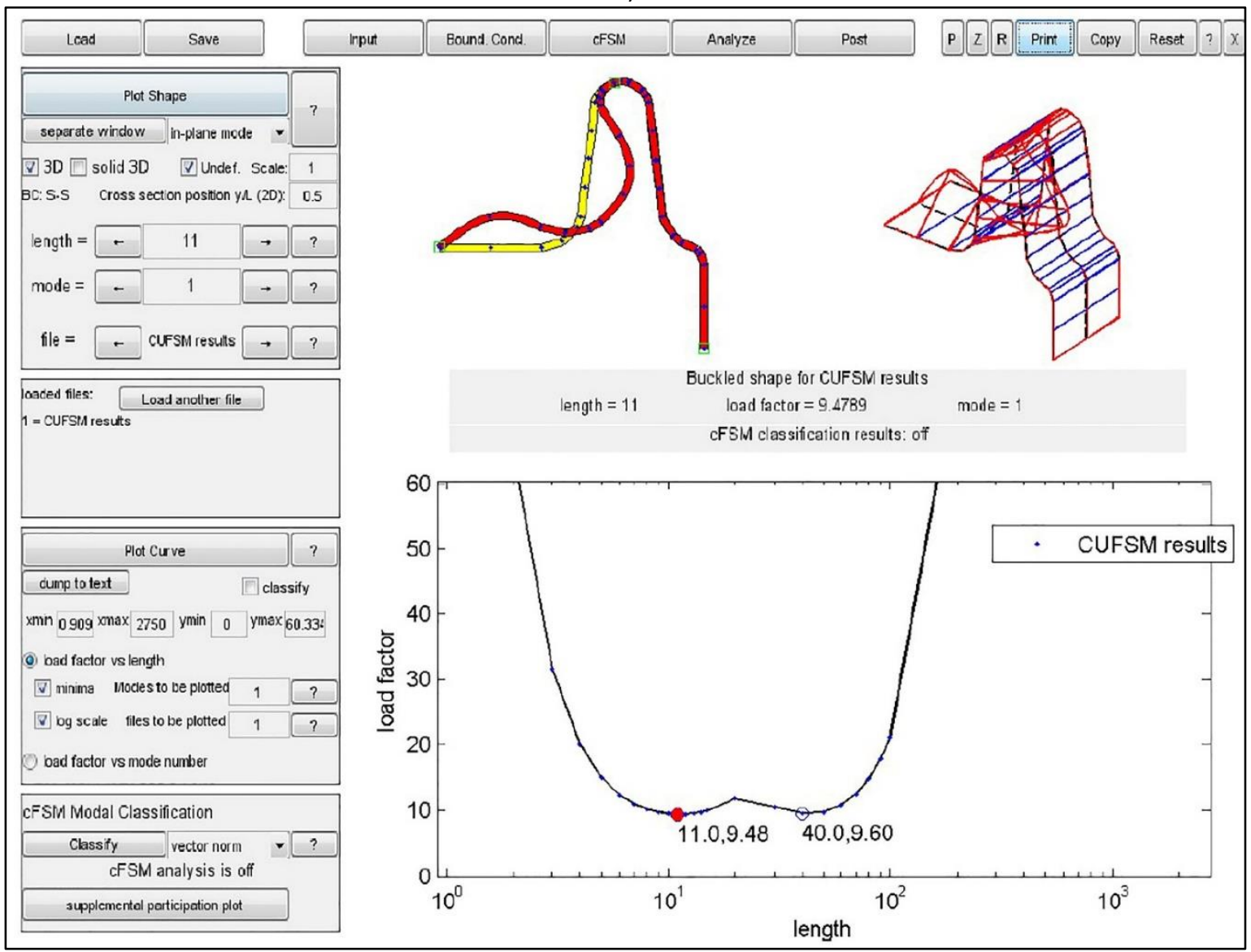

b)

The results of the analysis according to the formulation of DSM, show that the type of buckling that marks the behaviour of the folding is local buckling. 
Using the Direct Strength Method Section determine the nominal axil capacity of the member at distortional buckling (AISI, 2007):

$$
\begin{array}{ll}
\text { for } \lambda_{c} \leq 1.5 & \text { for } \lambda_{c} \triangleright 1.5 \\
P_{n e}=\left(0.658^{\lambda_{c}^{2}}\right) P_{y} & P_{n e}=\left(\frac{0.877}{\lambda_{c}^{2}}\right) P_{y}
\end{array}
$$

Nominal axial strength for local buckling:

$$
\begin{array}{ll}
\text { for } \lambda_{l} \leq 0.776 & \text { for } \lambda_{l} \triangleright 0.776 \\
P_{n l}=P_{n e} & \left.P_{n l}=\mid 1-0.15\left(\frac{P_{c r l}}{P_{n e}}\right)\right]^{0.4}\left(\frac{P_{c r l}}{P_{n e}}\right)^{0.4} P_{n e} \quad \text { where } \lambda_{l}=\sqrt{P_{n e} / P_{c r l}}
\end{array}
$$

Nominal axial strength for distortional buckling:

$$
\begin{array}{ll}
\text { for } \lambda_{d} \leq 0.561 & \text { for } \lambda_{d} \triangleright 0.561 \\
P_{n d}=P_{y} & P_{n d}=\left\lfloor 1-0.25\left(\frac{P_{c r d}}{P_{y}}\right)\right]^{0.6}\left(\frac{P_{c r d}}{P_{y}}\right)^{0.6} P_{y} \quad \text { where } \lambda_{d}=\sqrt{P_{y} / P_{c r d}} \quad \text { Eq. } 3
\end{array}
$$

Once the compression resistance of each one of the folds that form the joint have been obtained, we end up with a theoretical total of $30.36 \mathrm{kN}$.

Following the theoretical study, different tests have been performed corroborating the theoretical calculations of the panel system. The values obtained are greater. This makes sense as in the theoretical study neither the outer faces of the panel have been taken into account, only the folds at the joints, nor the contribution of the foam core in the increase of resistance.

Finally, several real-scale prototypes based on the conclusions obtained in this research have been built, implementing a structural analysis model based on digital prototyping of the whole, that may push forward industrialization in the field of construction.

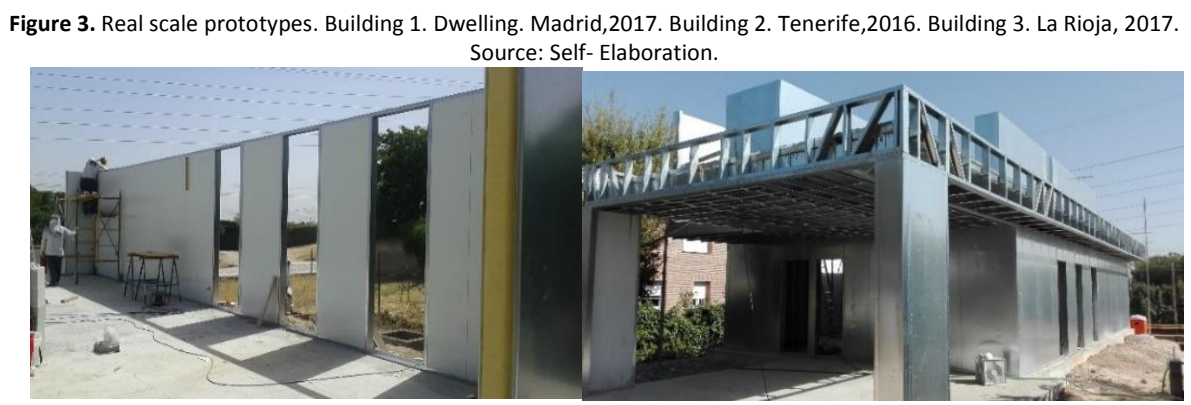

Building 1.

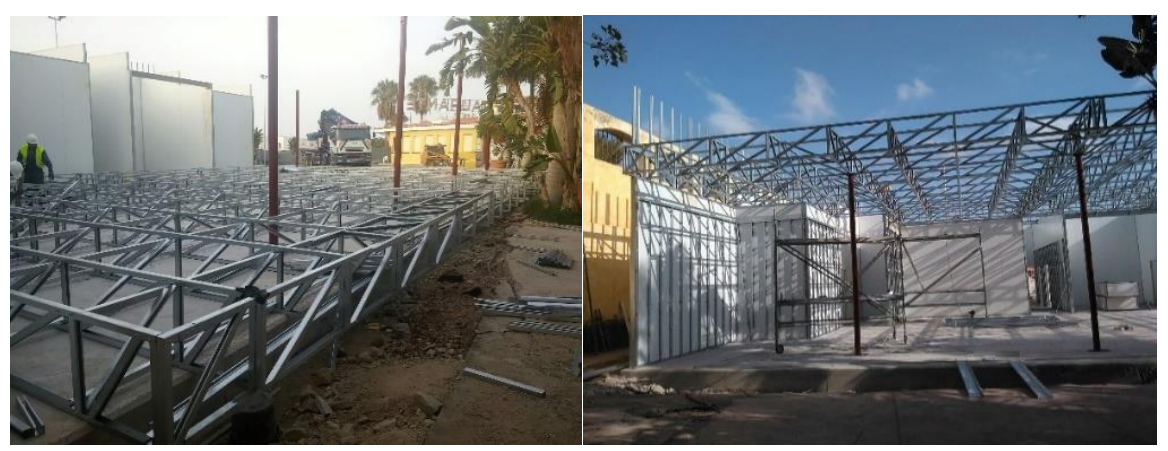

Building 2 


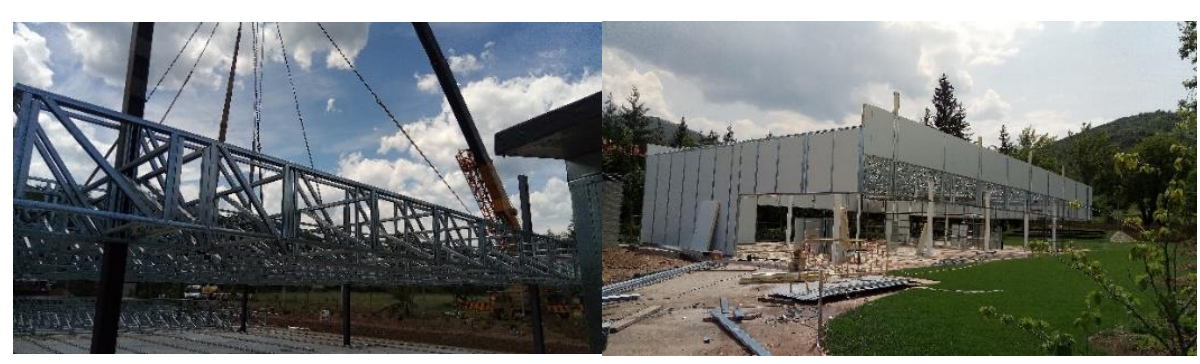

Building 3

The use of sandwich panels as bearing walls is still unregulated. First drafts of future standards are coming out as Eurocodes ECCS TC7 TWG 7.9 Sandwich Panels and Related Structures draft regulations.

\section{Theoretical advances in Sandwich panel research}

The largest research on sandwich panels to date has been done through the EASIE project financed by the European Union under the seventh framework program, number: FP7/NMP2-SE-2008, grant number: 213302r the seventh framework program with the number: FP7/NMP2-SE-2008, grant number: 213302.

Under this umbrella, recommendations have been made on the use of structural panels in construction areas. But the behaviour of the joint panel and the possible improvements.

With its anchoring solutions have not been studied. We want to take advantage of the tests described below, to corroborate the theoretical calculations and improve the results obtained in the EASIE program.

This type of behaviour in light structures that represents a trend in industrialized construction, has already been studied by diverse research groups at the level International (Koschade, 2006a). Highlight in addition to the German tendencies of the association "International Council for Research and innovation in Building and Construction", the American researches directed by B. Schafer in the group "Thin walled structures", and some aspect that studies the light and nonlight panel behavior introducing reinforcements of concrete and steel corrugated. These solutions open another way of investigation of the behavior of the composite material. After conclusions obtained in the tests carried out under the idea of light structure of easy assembly and industrialized are included possibilities of reinforcement in singular points (corners and joints).

The advances in parallel investigations within the same field of composite material with foam core and metal wall (Smith, Szyniszewski, Hajjar, Schafer, \& Arwade, 2012; Boccaccio, Casavola, Lamberti, \& Pappalettere, 2013; Hangai et al., 2014), collect similar conclusions in realizing the operation of the outer sheets and different material. There are comparable trials of behavior between steel and aluminum reaching similar conclusions. The aluminum is more moldable so has a better reception in various industrial sectors, while the steel follows regulations closer to the Eurocodes, closed to LGSF trends.

In addition, the emergence of 3d printers generates another way of future research (Fraile, 2014) and new predesigned lightweight composite materials to address any behavioral deficiencies tested in all open research at the international level. These printers currently support any counting type of material designing specific headers based on robotics and materials engineering (concretes, fibers and fabrics, foams, sheets, etc.) (Oxman, \& Mitchell, 2010; Menges, 2011; Fratzl \& Weinkamer, 2007).

The advances of robotics, artificial intelligence, techniques of scanning, and the computational geometry systems of all kinds of procedures, to allow for new free form structures (Nagy, Zhao, \& Benjamin, 2018; Griffith, 2006).Customized fabrication enable the process of digital design and industrial production (Eversmann, 2018). Therefore by studying the behaviors of current traditional designs, introducing their characteristics into a mathematical parametricism plus using Machine Learning capabilities, we can improve the characteristics of current products and implement production concepts, optimizing costs and design (Smigielska, 2018).

In this article we limit the essays to a typology of an existing panel, whose conclusions will allow to incorporate certain improvements in its industrial elaboration and assembly. In this way the construction tend to a robotics and a generation 3d solutions (Future, 2009). 
The sandwich panel to study is a panel with triple groove. This Panel has the following CE marking with the characteristics shown in Table 1.

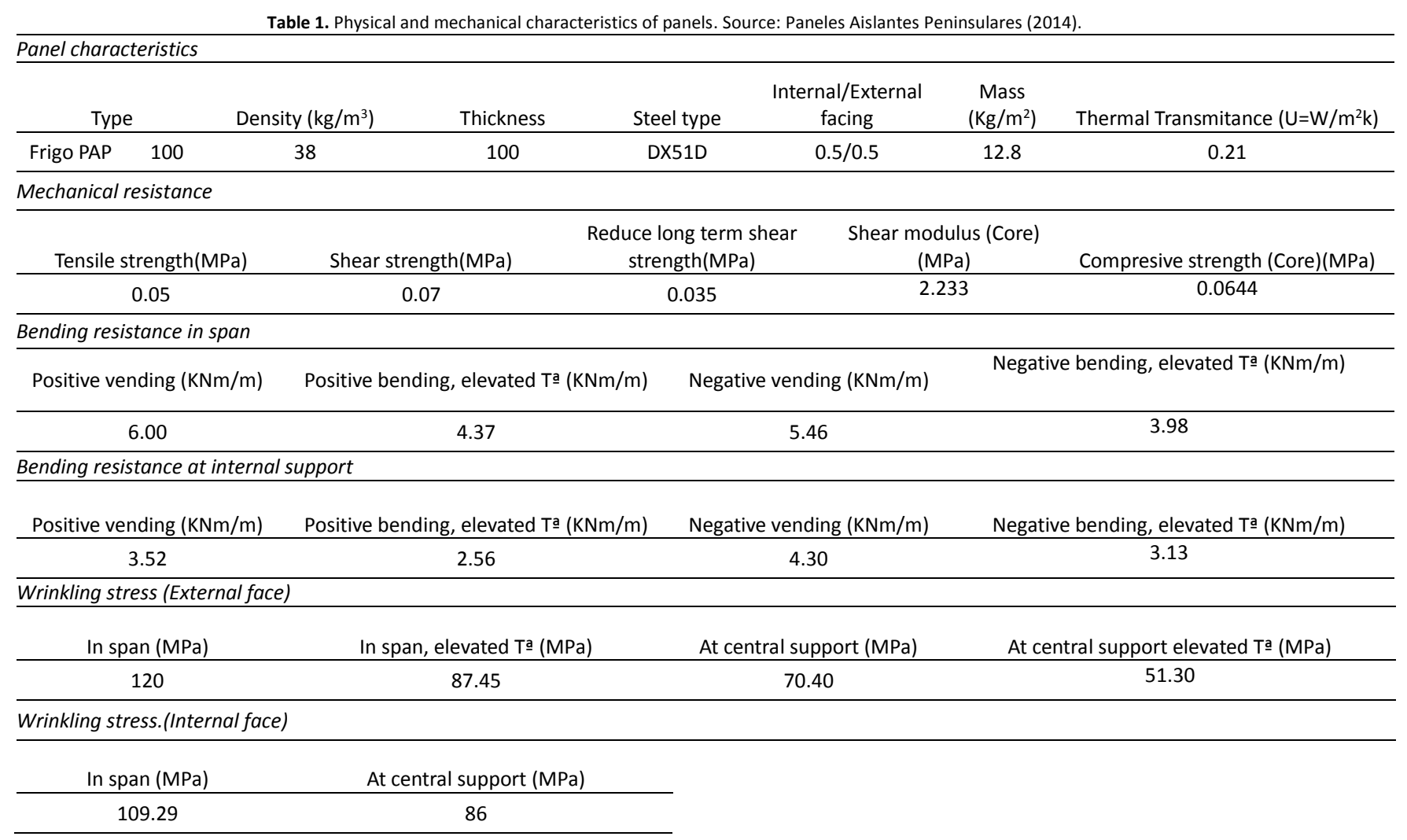

\section{Results and discussions}

This theoretical load model has been tested directly at the structures laboratory of the School of Architecture of Madrid (UPM).

The panel tests done at the laboratory verify the theoretical behaviour, enabling to optimize loading according to the different assembling of panels and LGSF profiles.

The goal is the study of compression behaviour of the tongue and groove joints of the panels and how they could be reinforced with the following three different sets of LGSF profiles.

Below are the layouts for the various laboratory tests (Figure 4).

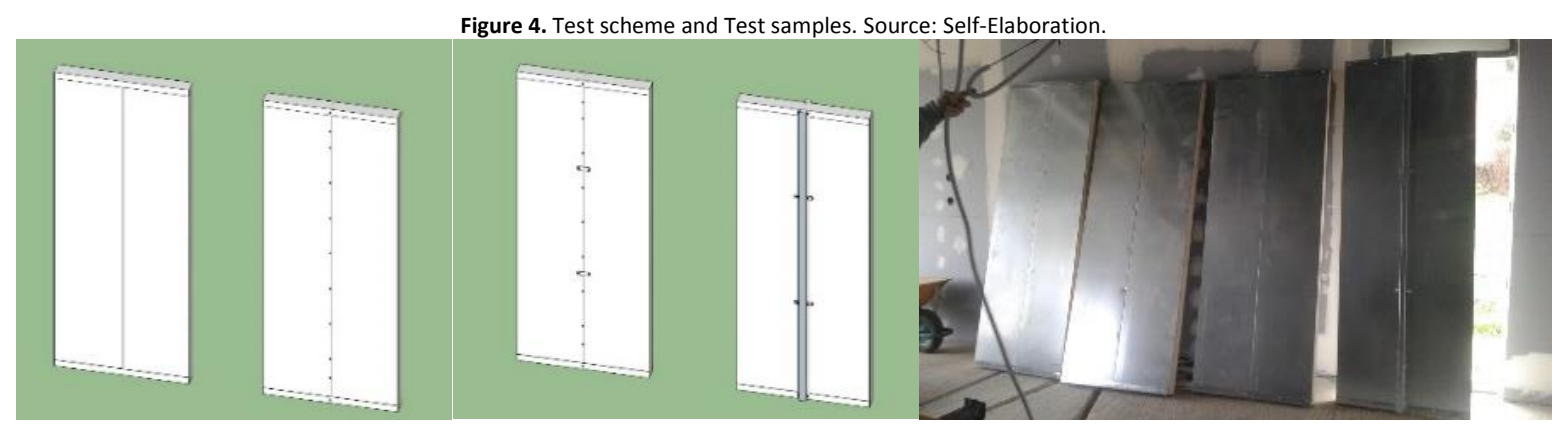

A galvanized steel $U$ profile (thickness $1.5 \mathrm{~mm}$ ) is screwed to the panel every $30 \mathrm{~cm}$, both lower and higher. The loading test of each one of them is carried out. The accepted loads and the displacement are recorded. This is the type of tests:

- $\quad$ Test 1: Sewn joint with screws every $30 \mathrm{~cm}$.

- $\quad$ Test 2: Simple joint. 
- $\quad$ Test 3: Sewn Joint with screws every $30 \mathrm{~cm}$ on plates on both sides of panels.

- $\quad$ Test 4: Sewn Joint with screws every $30 \mathrm{~cm}$ on hat profiles $30 \times 40 \times 1.5$ on both sides of panels.

These tests are shown in Figure 5 matching each type of test and the compression test graph. As shown in the tests, loads supported by the simple joint (Figure 5, test 2), without any type of reinforcement, reaches up to 5 tons and 16 mm displacement.

Figure 5. Test results images and graph. Order up to down Test 1, Test 2, Test 3, and Test 4. Order left to rigth, first figure start test and second
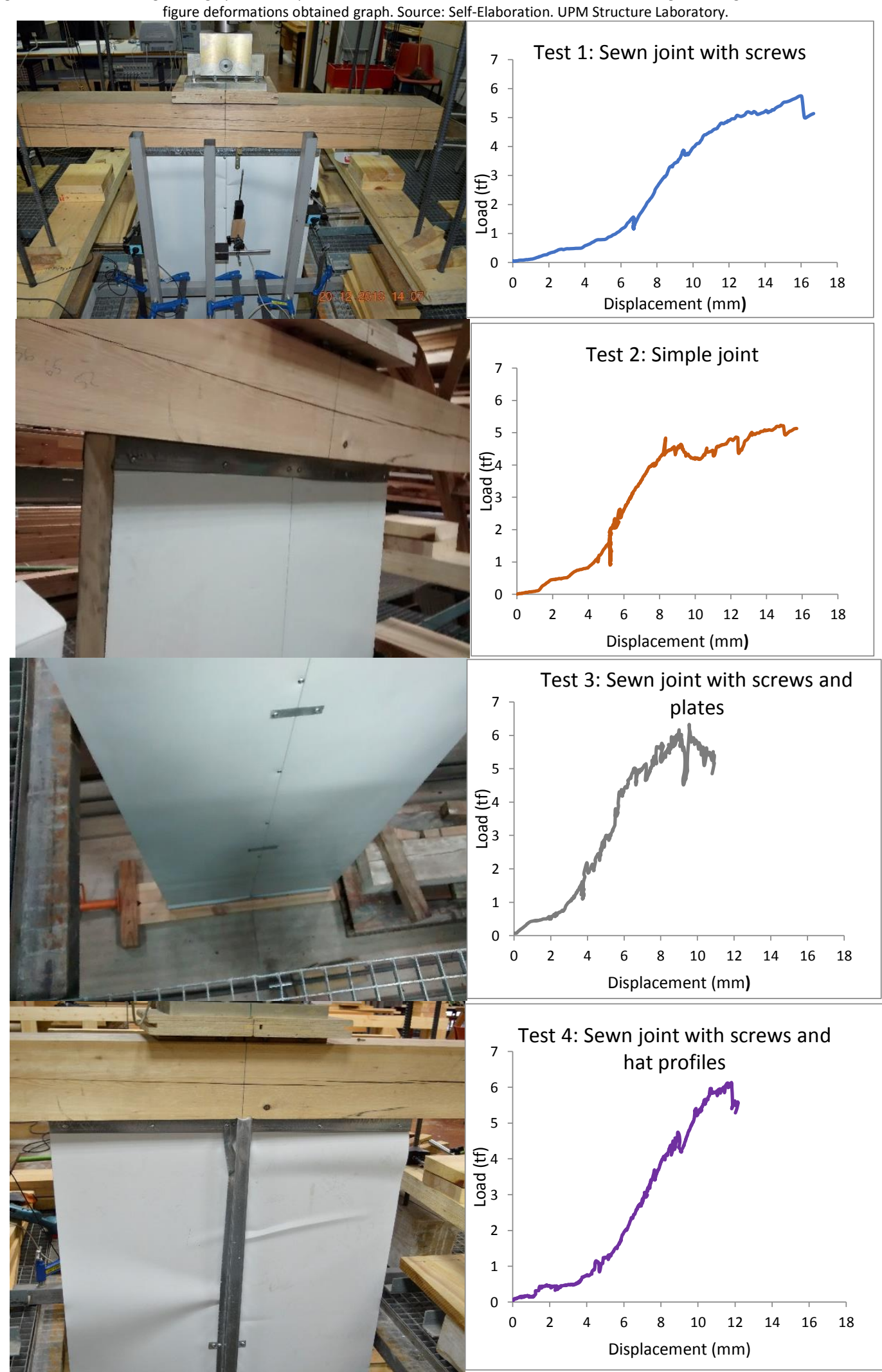
Test 3, in which the joint is reinforced with screws every $30 \mathrm{~cm}$ and plates on both sides of panel, shows to be a better solution. However, the attachment of a vertical hat profile does not improve significantly the behaviour of the basic test or test 2. It does raise the supporting capacity and minimizes the displacement to $4 \mathrm{~mm}$, but in fact it would be worth using it only in specific situations that call for some construction need.(Figure 6)

Similarly, as can be seen in Figure 5, test 4 gives very similar results to test 2 . Therefore, as a conclusion of the tests, under standard conditions of use the test 2 is the most suitable for general use, and can sometimes reinforce with the solution obtained in test 3 , the plates (Figure 6).

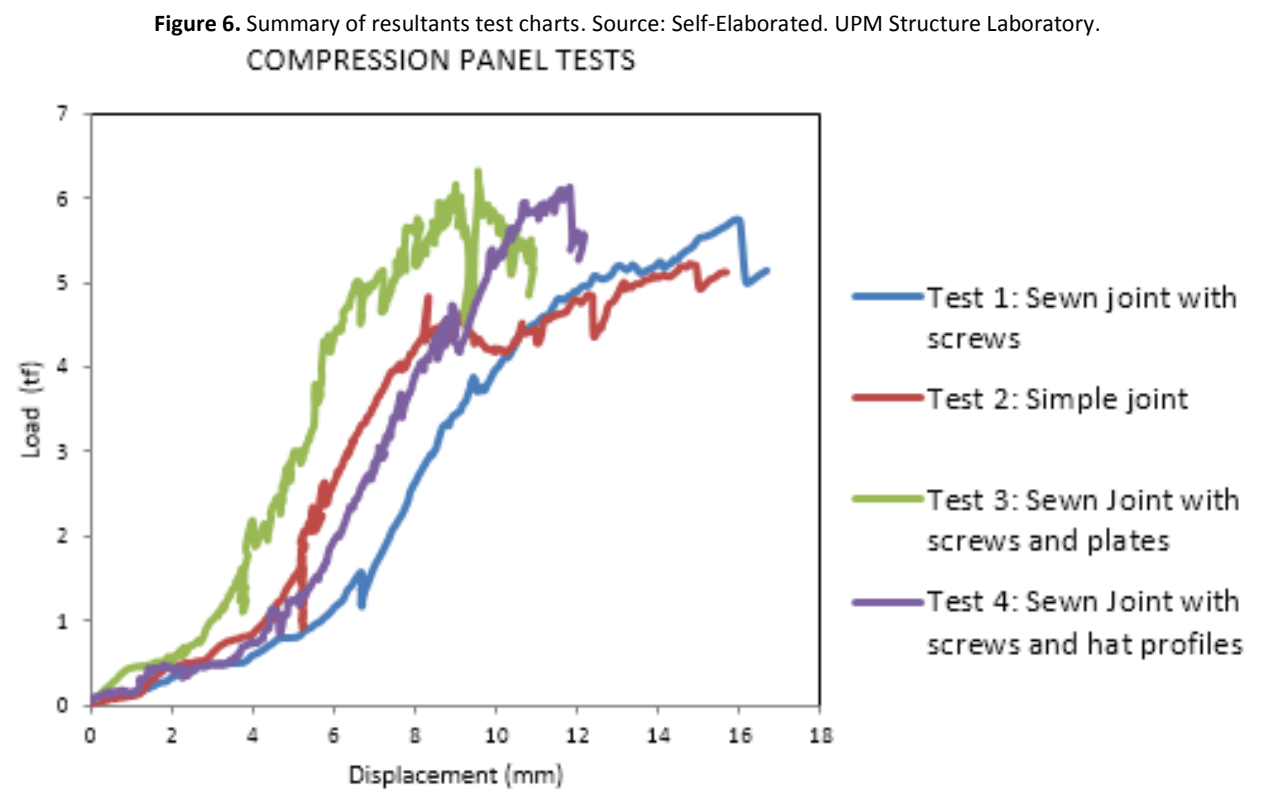

The solution with screws does not show a clear improvement from any point of view and seems to work slightly worse as far as displacement is concerned (Figure 5, test 1). Deformation is clearly high than in test 1 (Figure 7, test 1).

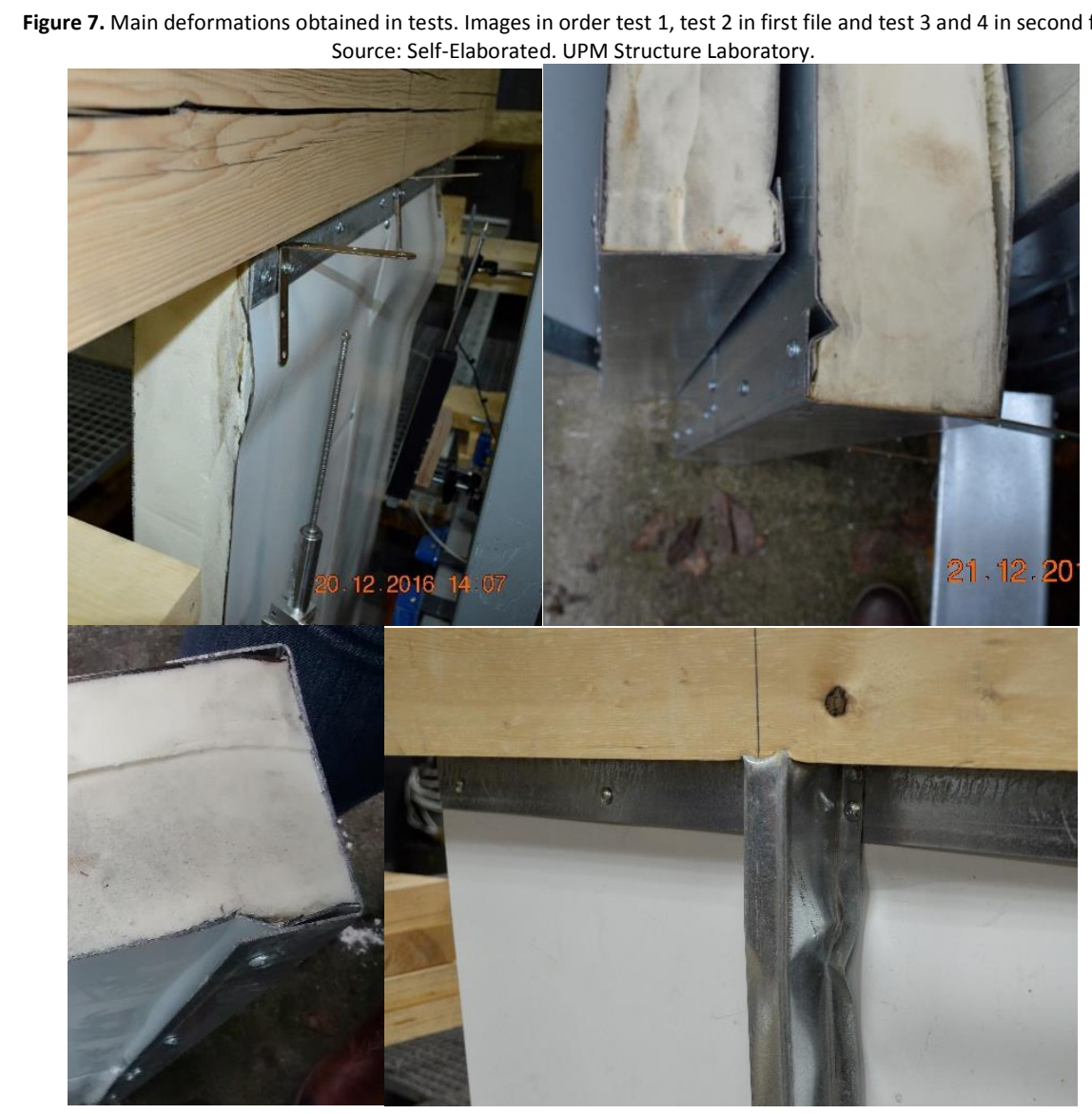


- As a conclusion of the comparison between theoretical and empirical models, we obtain an improvement in behavior in the tested empirical model. The theoretical value is $30.36 \mathrm{KN}$ versus $47.56 \mathrm{KN}$ get in tests. These values allow us to conclude that the model studied by finite elements with CUFSM program, always allows the calculation safely. Since in the empirical model we reach $50 \%$ higher loads.

- The design of the groove is supported as a vertical structure of LGSF light constructions, using the values collected in the tests as an extreme load. For practical design the deformations from bowing of the panel, from wind loads, from different temperatures at the faces and from the long term effects due to creep of the core layer are to be taken into account in each case. As practical design method is recommended the determination of the effects of action of 2 nd order theory.

- $\quad$ The permissible compression stresses of these structural joints correspond to the third part of the tested values, and therefore of $15.85 \mathrm{KN}$. With these calculation values is being built the current structures light up to 2 floors without the need to incorporate additional reinforcements. In reality, this is the empirical basis of a modular system of self-supporting carpentry, based on the structural joint of the panels studied. These panels, which through a system of dimensional coordination with the industrial systems, create a mechanism of panels that generate architecture.

- $\quad$ This study allows to leave a new line of research on the structural board and its horizontal behavior, which would allow the solution of the Trihedron structural (corner, vertical and horizontal). In this way and with the incorporation of certain reinforcements in the industrialization of the board we would be possible to eliminate part of the LGSF of the assembly of this solution, incorporating the sandwich solution in all the constructive directions.

- Through the studio of the Trihedron both horizontally and vertically, allowing empty or full gaps within the modular design, which allow the structural system to continue stable. We would achieve high structural and design capabilities, which would lead us to be able to create an architecture configurator by means of mathematical equations.

- $\quad$ This research is a constructive definition with light materials, high molding capacity, high resistance level, whose configuration as structural shell can be solved by self-supporting constructive elements produced with composites. The metal cored foam and whose assembly allows the conformation of continuous structural forms

Acknowledgments

The research described in this paper was financially supported by Purever Group and a CDTI (Centro para el Desarrollo Técnico e Industrial) investigation proyect (IDI-20150355). Acknowledgments to the structural laboratory of the Escuela Técnica Superior de Arquitectura de Madrid, Universidad Politécnica de Madrid.

References

AISI (2012). North American specification for the design of cold-formed steel structural members. AISIS100-12, American Iron and Steel Institute, Washington, DC, United States of America.

Anaya, J. (2014). The construction engineering of the digital design of free forms. Morphogenetic design strategies. In IABSE2014.

Boccaccio, A., Casavola, C., Lamberti, L., \& Pappalettere, C. (2013). Structural response of polyethylene foam-Based sandwich panels subjected to edgewise compression. Materials, 6(10), 4545-4564. https://doi.org/10.3390/ma6104545

Elipe, M. D. Á., \& Díaz, J. A. (2018). Review of contemporary architecture projects based on nature geometries [Revisión de proyectos de arquitectura contemporánea basados en geometrías de la naturaleza]. Revista de la Construccion, 17(2), 215-221. https://doi.org/10.7764/RDLC.17.2.215

Eversmann, P. (2018). Robotic Fabrication Techniques for Material of Unknown Geometry. In K. De Rycke, C. Gengnagel, O. Baverel, J. Burry, C. Mueller, M. M. Nguyen, ... M. R. Thomsen (Eds.). Humanizing Digital Reality: Design Modelling Symposium Paris 2017 (pp. 311-322). Singapore: Springer Singapore. https://doi.org/10.1007/978-981-10-6611-5_27

Fraile, M. (2014a). El nuevo paradigma contemporáneo. Del diseño paramétrico a la morfogénesis digital. In Teoría de la arquitectura en la $\begin{array}{lllll}\text { contemponaneidad. } & \text { (pp. } & \text { 2-11). Buenos } & \text { Argentina. }\end{array}$ https://www.academia.edu/2146376/EI_nuevo_paradigma_contempor\%C3\%A1neo._Del_dise\%C3\%B1o_param\%C3\%A9trico_a_la_morfog\% C3\%A9nesis_digital

Fraile, M. (2014b). Morfogénesis digital. Del diseño en serie al parametrismo eficiente. In Teoría de la arquitectura en la contemponaneidad. (Vol. VII, pp. 1-15). Buenos Aires, Argentina. Retrieved https://www.academia.edu/2714942/Morfog\%C3\%A9nesis_Digital._Del_Dise\%C3\%B1o_en_Serie_al_Parametrismo_Eficiente

Fratzl, P., \& Weinkamer, R. (2007). Nature's hierarchical materials. Progress in Materials Science, 52(8), $1263-6425$. 
Griffith, K. (2006). Design Computing of Complex-curved Geometry using Digital Fabrication Methods. Retrieved from https://core.ac.uk/download/pdf/4400068.pdf

Hangai, Y., Saito, M., Utsunomiya, T., Kitahara, S., Kuwazuru, O., \& Yoshikawa, N. (2014). Fabrication of aluminum foam-filled thin-wall steel tube by friction welding and its compression properties. Materials, 6(9), 6796-6810. https://doi.org/10.3390/ma7096796

Kolarevic, B. X. (2003). Digital Production. In Architecture in the digital age: design and manufacturing (pp. 38-63). Taylor \& Francis.

Koschade, R. (Institut für S. M. (2006a). Construction with factory engineered sandwich panels. (M. Institut für Sandwichtechnik, Ed.) (2006th ed.). Mainz, Germany.

Koschade, R. (Institut für S. M. (2006b). Construction with factory engineered Sandwich Panels. (iS- mainz, Ed.).

Li, Z., \& Schafer, B. W. (2010). Buckling analysis of cold-formed steel members with general boundary conditions using CUFSM: Conventional and constrained finite strip methods. Proceedings Twentieth International Specialty Conference on Cold-Formed Steel Structures, 17-31. https://doi.org/10.1016/j.tws.2006.03.013

Lundquist, Eugene E. \& Stowell, Elbidge Z. (1941). Critical compressive stress for flat rectangular plates supported along all edges and elastically restrained against rotation along the unloaded edges. Special Report 189. National Advisory Commetee for Aeronautics. Langley Field, Va. (733). https://ntrs.nasa.gov/search.jsp?R=20090015033

Menges, A. (2011). Simple Systems - Complex Capacities. Integrative Processes of Computational Morphogenesis in Architecture. TECHNE - Journal of Technology for Architecture and Environment, 1(2), 68-77. Retrieved from http://www.fupress.net/index.php/techne/article/view/9928

Nagy, D., Zhao, D., \& Benjamin, D. (2018). Nature-based hybrid computational geometry system for optimizing component structure. In K. De Rycke, C. Gengnagel, O. Baverel, J. Burry, C. Mueller, M. M. Nguyen, ... M. R. Thomsen (Eds.). Humanizing Digital Reality: Design Modelling Symposium Paris 2017 (pp. 167-176). Singapore: Springer Singapore. https://doi.org/10.1007/978-981-10-6611-5_15

Smigielska, M. (2018). Application of machine learning within the integrative design and fabrication of robotic rod bending processes. In K. De Rycke, C. Gengnagel, O. Baverel, J. Burry, C. Mueller, M. M. Nguyen, ... M. R. Thomsen (Eds.), Humanizing Digital Reality: Design Modelling Symposium Paris 2017 (pp. 523-536). Singapore: Springer Singapore. https://doi.org/10.1007/978-981-10-6611-5_44

Smith, B.H., Arwade, S.R., Schafer, B.W., \& Moen, C. D. (2016). Design component and system reliability in a low-rise cold formed steel framed commercial building. Engineering Structures, 127(1410296), 434-446. https://doi.org/10.1016/j.engstruct.2016.08.049

Smith, B., Szyniszewski, S., Hajjar, J., Schafer, B., \& Arwade, S. (2012). Characterization of Steel Foams for Structural Components. Metals, 2(4), 399410. https://doi.org/10.3390/met2040399

Timoshenko, S. \& Gere, P. (1936). Theory of Elastic Stability, New York. Theory of Elastic Stability. New York.

Winter, G. (1952). Light gauge (thin-walled) steel structures for building in the USA Preliminary publication. In 4th Congress of the International Association for Bridge. Chicago.

Yu, C., \& Chen, H. (2016). Recent code development and design standards for cold-formed steel structures. In Recent Trends in Cold-Formed Steel Construction (pp. 39-51). Elsevier. https://doi.org/10.1016/B978-0-08-100160-8.00002-5 